\title{
The Photosynthetic Physiological Responses of Leaves from Different Shoots of Taxus Cuspidata to Elevated $\mathrm{CO}_{2}$
}

\author{
Qige Qi /Beihua University \\ Forestry College \\ Jilin City, China \\ E-mail: qqgsun@sina.com
}

\author{
Lihua Zhong /Beihua University \\ Educational Center of College Mathematics \\ Jilin City, China \\ E-mail: $\underline{2353665912 @ q q . c o m}$
}

\begin{abstract}
Net photosynthetic rate (PN), transpiration rate (E), stomatal conductance (Cond), intercellular $\mathrm{CO}_{2}$ concentration $(\mathrm{Ci})$, and vapor pressure deficit on the surface (VPD) of Taxus cuspidata leaves set at a series of $\mathrm{CO}_{2}$ concentration were investigated with the LI-COR 6400 portable photosynthesis system. For the annual shoot and the biennial shoots and blades, both PN and $E$ increased with the increase in $\mathrm{CO}_{2}$ concentration, but the increase in PN was larger than that in $\mathrm{E}$. The maximal PN of the annual shoot $\left(6.95 \mu \mathrm{mol} \cdot \mathrm{m}^{-2} \cdot \mathrm{s}^{-1}\right)$ was larger than that of the biennial shoot $\left(6.87 \mu \mathrm{mol} \cdot \mathrm{m}^{-2} \cdot \mathrm{s}^{-1}\right)$ at a $\mathrm{CO}_{2}$ concentration as high as $1400 * 10-6$. $E$ of the annual shoot was slightly larger than the biennial shoot but with no big disparity. Water use efficiency (WUE=PN/E) of the annual and biennial shoots went up with $\mathrm{CO}_{2}$ concentration. WUE of the annual shoot was slightly higher than the biennial shoot, yet without significant disparity. The significant ascent of PN played a major role in the WUE of Taxus cuspidata going up with the elevated $\mathrm{CO}_{2}$ concentration.
\end{abstract}

Keywords-Taxus Cuspidata; Annual Shoot; Biennial Shoot; $\mathrm{CO}_{2}$ Concentration

\section{INTRODUCTION}

Taxus cuspidata of the family Taxaceae and genus Taxus is the precious relict species from Quaternary Period $^{[1]}$. It is mainly distributed in the red pine and broad leaved forests of Changbai Mountains and east Liaoning Province at the altitude of $500 \sim 1,000$ meters. Fifty years ago, there were large areas of adult trees, but due to illegal logging for its excellent quality wood it is now even hard to find. It is superior in texture, structure, elasticity, material strength, glossiness, fragrance, and anti-decay, easy to shape, poor cracking and springing, and free from resin. Its sapwood is yellowish white, while the heartwood is dark reddish brown. It has good performance for coloring and painting, thus suitable for making musical instruments, engraving, high quality furniture and artistic decoration. Apart from the plant alkaloid "taxin" ${ }^{[2,3]}$, it

\author{
Qichang Zhang*/Beihua University \\ Forestry College \\ Jilin City, China \\ e-mail:zqc1212@sina.com \\ * Corresponding Author \\ Xueting Zheng /Beihua University \\ Forestry College \\ Jilin City, China \\ E-mail: zhengxt@sina.com
}

also contains the highly toxic essential oil. However, its aril is slightly sweet and edible, whereas gum material can be extracted from its bark, chip, and seeds. The tree has elegant shape, red fruit, and dense green foliage in four seasons, and can be planted in gardens as ornamental trees. Its root, stem, leaves, and bark can be used as medicine, the leaves being diuretic, effective in treating hypertension, diabetes and heart disease $\mathrm{e}^{[4]}$.

$\mathrm{CO}_{2}$, water, and photosynthetic radiation serve as not only the basic matter and energy for plant physiological activities, but also the important ecological factors that affect plant growth, development, reproduction and distribution. Studies have shown that different types of shoots of identical or different species express significant differences in response to changes in environmental conditions. This difference is part of the plant' s strategies for survival and competition, and significantly affects the plant in resource acquisition, utilization and distribution, and ultimately affects the vegetation composition and succession ${ }^{[5]}$. Currently, atmospheric $\mathrm{CO}_{2}$ concentration on Earth has reached $360 \mu \mathrm{l} / \mathrm{L}$, about $30 \%$ higher than before the Industrial Revolution, and is expected to double in the second half of the 21st century. The rise of global atmospheric $\mathrm{CO}_{2}$ concentration will have a profound impact on the ecosystem, and the possible effects of the change in $\mathrm{CO}_{2}$ has become a major concern of plant physiological ecologists ${ }^{[6-11]}$.

The paper expounds the findings on the annual and biennial shoots and blades in their different responses to the ambient changes in $\mathrm{CO}_{2}$ concentration by observing and comparing physiological indices in relation to the elevating $\mathrm{CO}_{2}$ concentration. Measuring photosynthetic physiology and water physiology of Taxus cuspidata will provide basic data for further studies on Taxus cuspidata carbon balance and photosynthesis mechanism. 


\section{STUDY AREA AND METHODS}

\section{A. Study area}

The experiment was conducted on June 10, 2005 in the Forestry College of Beihua University, located in the eastern mountain area of Jilin Province. The region has a temperate continental monsoon climate with four distinct seasons. It is rainny and dry in spring, warm and rainy in summer, cool and sunny in autumn, and cold in the long winter. The annual average temperature is $3-5{ }^{\circ} \mathrm{C}$, extreme annual maximal high $36.6^{\circ} \mathrm{C}$, and maximal low $-45^{\circ} \mathrm{C}$. The frost-free period is up to $130-140 \mathrm{~d}$, annual rainfall 650 $750 \mathrm{~mm}$, sunshine duration $2400-2600 \mathrm{~h}$, and annual total radiation $1150 \mathrm{k} / \mathrm{mm} 2$.

\section{B. Methods}

A portable LI-6400 photosynthesis infrared gas analyzer (LI-6400P, LI-COR Inc.) made by LI-COR and LI6400-01 $\mathrm{CO}_{2}$ Injector were used to measure net photosynthetic rate $(\mathrm{PN})$, transpiration rate $(\mathrm{E})$, stomatal conductance (Cond), intercellular $\mathrm{CO}_{2}$ concentration $(\mathrm{Ci})$ and foliar saturated vapor pressure deficit (VPD) in the annual and biennial shoots and leaves of Taxus cuspidata set at different $\mathrm{CO}_{2}$ concentration. $\mathrm{CO}_{2}$ concentration gradient was set to be $(50,100,200,400,600,800,1000$, $1200,1400,1600) * 10^{-6}$. With each change in $\mathrm{CO}_{2}$ concentration, the minimal stable time was set to be $120 \mathrm{~s}$. The variation rate, when measured to be less than 0.05 , was to be automatically recorded by an infrared gas analyzer, and repeated three times. Taxus cuspidata has finer blades, resulting in relatively big errors in a single blade measurement. A number of blades were to be placed together in the leaf compartment for measurement, graph paper used to measure the accurate leaf area, with measurements entered before the results got analyzed in Excel.

\section{RESULTS AND ANALYSES}

\section{A. Stomatal conductance}

Stomatal serve as the channel for leaf to exchange matter with the air, and the degree of stomatal closure will significantly affect plants' fixed $\mathrm{CO}_{2}$ transpiration rate and water loss. As ambient $\mathrm{CO}_{2}$ concentration increased, annual and biennial stomatal conductance (Cond) showed a downward trend, with no significant decline when $\mathrm{CO}_{2}$ concentration was $(50-800) * 10^{-6}$, and a significant decrease when $\mathrm{CO}_{2}$ concentration exceeded 800*10-6. Annual shoots' stomatal conductance was slightly larger than biennial shoots (Figure 1). The relationship between stomatal conductance and $\mathrm{CO}_{2}$ concentration fitted well in a quadratic equation, correlation coefficients being -0.9608 and -0.9665 (Table 1).

\section{B. Intercellular $\mathrm{CO}_{2}$ concentration}

Intercellular $\mathrm{CO}_{2}$ concentration $(\mathrm{Ci})$ in the annual and biennial blades went up as ambient $\mathrm{CO}_{2}$ concentration increased. $\mathrm{Ci}$ in the annual blade was slightly larger than that in the biennial blade (Figure 2). Both $\mathrm{Ci}$ to $\mathrm{CO}_{2}$ response equations were linear equations, showing a positive correlation, with coefficient of 0.9961 and 0.9957 respectively (Table 1). Experimental results suggested that

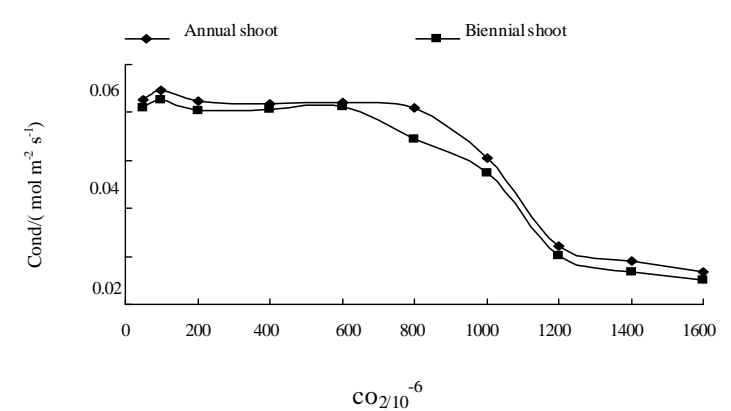

Figure 1. The stomatal conductance responses of leaves from different shoots of Taxus cuspidata to elevated $\mathrm{CO}_{2}$

the impact of ambient $\mathrm{CO}_{2}$ concentration on $\mathrm{Ci}$ was significant, and that partial pressure of atmospheric $\mathrm{CO}_{2}$ caused $\mathrm{CO}_{2}$ to enter into the intercellular rate of leaf photosynthetic tissue, thereby affecting the amount and rate of fixed $\mathrm{C}$ in plant leaf photosynthesis.

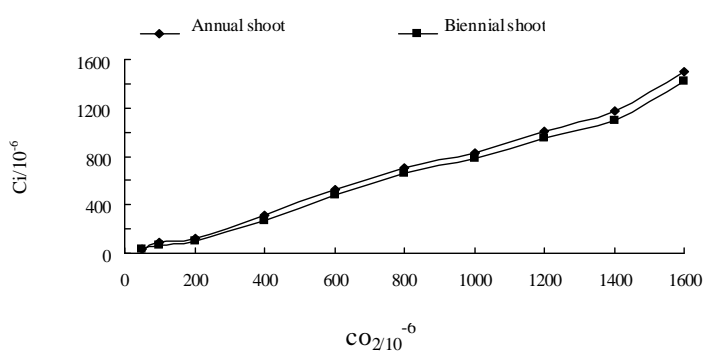

Figure 2. The intercellular $\mathrm{CO}_{2}$ responses of leaves from different shoots of Taxus cuspidata to elevated $\mathrm{CO}_{2}$

\section{Foliar saturated vapor pressure deficit}

Foliar saturated vapor pressure deficit (VPD) was affected by the foliar minor environmental changes in water vapor pressure, and was closely related to the transpiration loss of plant foliage. VPD in the annual and biennial foliage showed an upward trend in the initial stage of elevating $\mathrm{CO}_{2}$ concentration. Both VPD values declined (Figure 3) when $\mathrm{CO}_{2}$ concentration was more than $1000 \mu$ mol/mol. A feedback mechanism existed among VPD, Cond, and $\mathrm{E}$ to regulate foliar transpiration and moisture loss. VPD serves as the driving force resulting in transpiration, and when the water loss exceeds the allowable range, blades limit it by regulating stomatal conductance, so as to achieve the effective use of limited moisture. The relationship between the VPD and $\mathrm{CO}_{2}$ concentration fitted well in a quadratic equation, correlation coefficients being 0.9706 and 0.9617 respectively (Table 1 ). 


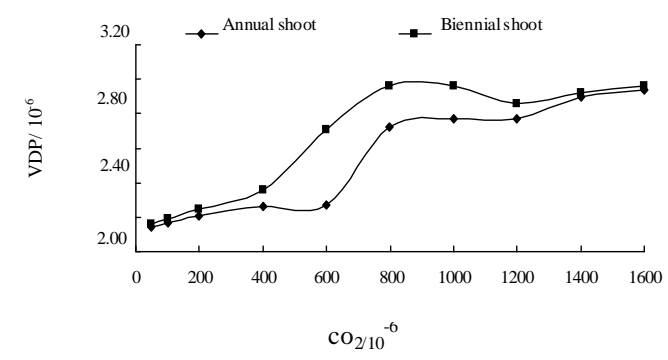

Figure 3. The VPD responses of leaves from different shoots of Taxus cuspidata to elevated $\mathrm{CO}_{2}$

\section{Responses of transpiration rate and net hotosynthetic rate to the changes in $\mathrm{CO}_{2}$ concentration}

\section{(1) Transpiration rate}

Transpiration rate (E) in the annual and biennial shoots and blades of Taxus cuspidata gradually increased with the increase of $\mathrm{CO}_{2}$ concentration in the leaf compartment, and within the range of measurement of $\mathrm{CO}_{2}$ concentration, $\mathrm{E}$ of the annual shoots was slightly larger than the biennial ones (Figure 4). When $\mathrm{CO}_{2}$ concentration increased from $50 \mu \mathrm{mol} / \mathrm{mol}$ to $1600 \mu \mathrm{mol} / \mathrm{mol}$, E of the annual shoots rose from $1.31 \mathrm{~mol} \cdot \mathrm{m}^{-2} \cdot \mathrm{s}^{-1}$ to $1.94 \mathrm{~mol} \cdot \mathrm{m}^{-2} \cdot \mathrm{s}^{-1}, 0.63 \mathrm{~mol} \cdot \mathrm{m}^{-2} \cdot \mathrm{s}^{-1}$ up. E of the biennial shoots rose from $1.24 \mathrm{~mol} \cdot \mathrm{m}^{-2} \cdot \mathrm{s}^{-1}$ to $1.92 \mathrm{~mol} \cdot \mathrm{m}^{-2} \cdot \mathrm{s}^{-1}, 0.68 \mathrm{~mol} \cdot \mathrm{m}^{-2} \cdot \mathrm{s}^{-1}$ up. Both response equations to the elevating $\mathrm{CO}_{2}$ concentration were logarithmic equations, correlation coefficients being 0.9715 and 0.9758 respectively (Table 1 ).

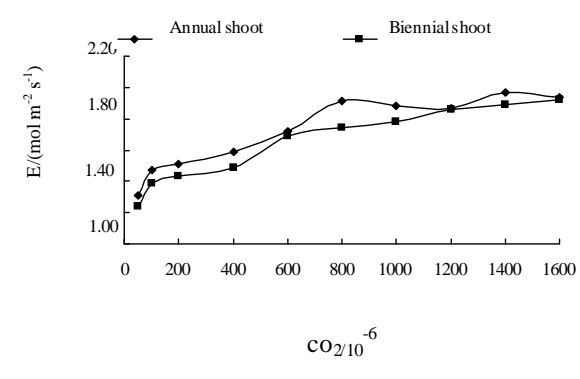

Figure 4. The transpiration rate responses of leaves from different shoots of Taxus cuspidata to elevated $\mathrm{CO} 2$

\section{(2)Net photosynthetic rate}

$\mathrm{CO}_{2}$ is one of the important raw materials for photosynthesis, and the atmospheric $\mathrm{CO}_{2}$ concentration will significantly affect net photosynthetic rate of plant leaves (PN). As the $\mathrm{CO}_{2}$ concentration increased, $\mathrm{PN}$ in the annual and biennial shoots showed an upward trend (Figure 5). Both response curves to the elevating $\mathrm{CO}_{2}$ concentration were logarithmic curves, correlation coefficients being 0.9709 and 0.9758 respectively (Table 1). $\mathrm{PN}$ average of the annual shoots at the given $\mathrm{CO}_{2}$ concentration was $5.553 \mu \mathrm{mol} \cdot \mathrm{m}^{-2} \cdot \mathrm{s}^{-1}$; PN average of the biennial shoots was $5.072 \mu \mathrm{mol} \cdot \mathrm{m}^{-2} \cdot \mathrm{s}^{-1}$. As can be seen, PN of the annual shoots was larger than that of the biennial ones, showing the two kinds of shoots differ in physiological function.

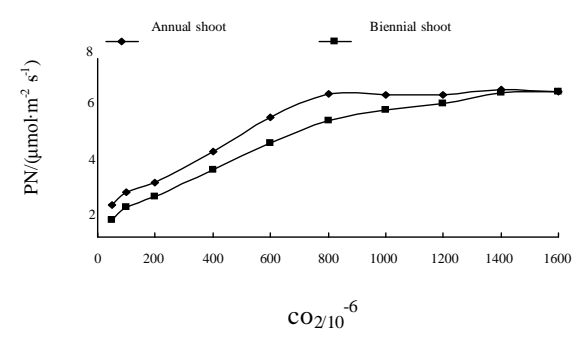

Figure 5. The net photosynthetic rate responses of leaves from different shoots of Taxus cuspidata to elevated $\mathrm{CO}_{2}$

\section{E. Instantaneous water use efficiency}

Water use efficiency (WUE) in both annual and biennial shoots and blades of Taxus cuspidata increased with the increase of $\mathrm{CO}_{2}$ concentration (Figure 6). Both response equations to the elevating $\mathrm{CO}_{2}$ concentration were logarithmic curve equations, correlation coefficients being 0.9543 and 0.9787 respectively (Table 1 ). WUE was determined by the ratio of PN and E. Thus, the changes of $\mathrm{PN}$ and $\mathrm{E}$ were to affect WUE. Experimental results showed that although PN of the annual shoots and blades was more than that of the biennial ones, transpiration consumption was equally enormous, resulting in WUE average in the annual shoots and blades being slightly higher than the biennial ones, with no significant difference.

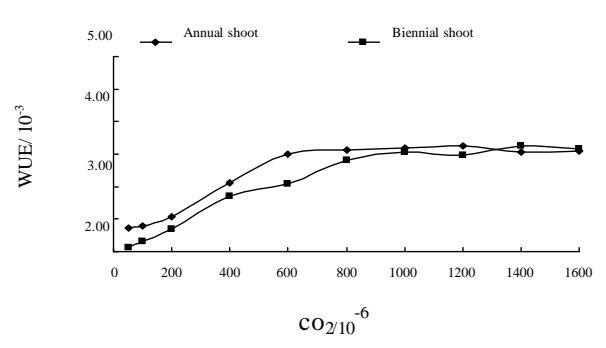

Figure 6. The water use efficiency responses of leaves from different shoots of Taxus cuspidata to elevated $\mathrm{CO} 2$

\section{CONCLUSION AND DISCUSSION}

The results of this experiment showed that the photosynthetic indexes in the annual Taxus cuspidata shoots were slightly larger than the biennial ones, and the growth of annual shoots were significantly greater than biennial ones. Net photosynthetic rate $(\mathrm{PN})$, transpiration rate $(\mathrm{E})$, intercellular $\mathrm{CO}_{2}$ concentration $(\mathrm{Ci})$ and foliar saturated vapor pressure deficit (VPD) of the two types of shoots and blades showed a positive correlation with $\mathrm{CO}_{2}$ concentration, while stomatal conductance (Cond) showed a negative correlation with $\mathrm{CO}_{2}$ concentration. However, 
as there was no much difference, so the impact of elevating $\mathrm{CO}_{2}$ concentration on the two types of shoots was not big.

Many studies have concluded that as the ambient $\mathrm{CO}_{2}$ concentration increases $\mathrm{CO}_{2}$ can enter the mesophyll cells more easily. To reduce the loss of the limited water, plant leaves usually close pores to some extent, lowering Cond to reduce $E[12]$. This study showed that the average $E$ in the two types of shoots rose, and that under the condition of high $\mathrm{CO}_{2}$ concentration the reduction of Cond did not lead to lower E. This may be the result of the impact of larger VPD as VPD is the driving force[13] for water to evaporate from the leaf into the air.

\section{ACKNOWLEDGMENT}

The research was financed by the department of education of Jilin Province science foundation projects (No. 2011133), National Natural Science Foundation Project(No.30271101) and the Jilin Province science foundation projects(No. 20060553).

\section{REFERENCES}

[1] Bai,G.X.,Wu,B.H.,and Zhang,Q.C. "Research in Taxus cuspidata," Beijing: China Forestry Publishing house, 2000.

[2] Wei Qiang, Zhang Guosheng, Liu Jinqi, et al."Research Progress of Chemical Components in Taxus Spices,'Guangzhou Chemical Industry, 2014, 42(6) : 17-23

[3] Wu Di, Li Ya-nan, Wu Li-jun2, Gao Hui-yuan. "Isolation and identification of chemical constituents from Taxus cuspidata Sibe et Zucc. Acta Pharmaceutica Sinica,” 2010, 45(11): 1398-1401.

[4] Lili Ge, Qige Qi, Qichang Zhang, Chunyan Guo. "Content Changes of Endogenous Hormones in Taxus cuspidata during the Flower Development," 2013 1nd International Conference on Biomedical Engineering and Environmental Engineering,2013,683-690
[5] Sun Wei, Wang De-Li. Wang Li, Yang Yun-Fei. "Responses in the transpiration properties and water use efficiency of leaves from dif ferent shoots of Stipa bacailens is to instantaneous changes in the $\mathrm{CO} 2$ concentrations and photosynthetic radiation," Acta Ecologica Sinica, 2004, 24(11): 2437-2443.

[6] Jiang Gao-Ming and Qu Chun-Mei. "Photosynthetic response of six woody species to elevated $\mathrm{CO}_{2}$ in Quercus liaotungensis forest in the Beijing mountainous areas," Acta Phytoecologica sinsca. 2000, 24(2): 204-208.

[7] Feng Yulong, Wang Lihua, Ao Hong, Nie Jiangli, Wang Wenzhang. " $\mathrm{CO}_{2}$ responses of physiological ecology characteristics in larix olgensis henry and its significance," Bulletin of Botanical Research, 1999,19(1):53-59.

[8] Wang Miao, Hao Zhanqing, Ji Lanzhu, Zhou Guangsheng. "Effect of elevated atmospheric $\mathrm{CO}_{2}$ concentrations on photosynthesis light response characteristics of three coniferous tree species seedlings," Chinese Journal of Applied Ecology, 2002, 13(6): 646650 .

[9] Han Shijie, Zhou Yumei, Wang Chenrui, Zhang Junhui, Zou Chunjing. "Ecophysiological response of Pinus koraiensis seedlings to elevated $\mathrm{CO}_{2}$," Chinese Journal Of Applied Ecology, 2001, 12(1): 27-30.

[10] Zheng Fengying, Peng ShaoLin. "Meta-analysis of the Response of Plant Ecophysiological Variables to Doubled Atmospheric $\mathrm{CO}_{2}$ Concentrations," Acta Botanica Sinica, 2001, 43(11): 1101-1109.

[11] Tian Dalun, Luo Yong, Xiang Wenhua, Yan Wende. "Photosynthetic Characteristics ofCinnamomum camphoraand Its Response to Elevation of $\mathrm{CO}_{2}$ and Temperature," Scientia Silvae Sinica, 2004,40(5):88-92.

[12] Wang Li, Yang YunFei, Sun Wei, Wang Deli. "Photosynthetic physiological response of two ecotypes of leymus chinensis to the double concentration of $\mathrm{CO}_{2,}$, Acta Agrestia Sinica, 2003, 11(1): 52-57.

[13] Sun Wei, Wang Deli, Wang Li, Yang YunFei. "A comparison of transpiration characteristics and water use ef $\mathrm{f}$ iciency between poaceae plants and chenopodiaceae plants under the simulated 1 ight source," Acta Ecologica Sinica, 2003, 23(4): 814-819. 
TABLE I RESPONSE EQUATIONS OF PHYSIOLOGICAL PARAMETERS OF ANNUAL AND BIENNIAL SHOOTS OF TAXUS CUSPIDATA TO THE ELEVATING $\mathrm{CO}_{2}$ CONCENTRATION

\begin{tabular}{lclll}
\hline Shoot type & Y & X & Equations & R \\
\hline Annual shoots & $\mathrm{Cond} /(\mathrm{mol} \cdot \mathrm{m}-2 \cdot \mathrm{s}-1)$ & $\mathrm{CO}_{2}$ & $\mathrm{y}=-2 \mathrm{E}-08 \mathrm{x} 2+5 \mathrm{E}-06 \mathrm{x}+0.0637$ & $\mathrm{R}=-0.9608$ \\
Biennial shoot & $\mathrm{Cond} /(\mathrm{mol} \cdot \mathrm{m}-2 \cdot \mathrm{s}-1)$ & $\mathrm{CO}_{2}$ & $\mathrm{y}=-2 \mathrm{E}-08 \mathrm{x} 2+7 \mathrm{E}-07 \mathrm{x}+0.0625$ & $\mathrm{R}=-0.9665$ \\
Annual shoots & $\mathrm{Ci}(10-6)$ & $\mathrm{CO}_{2}$ & $\mathrm{y}=0.8982 \mathrm{x}-31.783$ & $\mathrm{R}=0.9961$ \\
Biennial shoot & $\mathrm{Ci}(10-6)$ & $\mathrm{CO}_{2}$ & $\mathrm{y}=0.8558 \mathrm{x}-44.141$ & $\mathrm{R}=0.9957$ \\
Annual shoots & $\mathrm{VPD}(10-6)$ & $\mathrm{CO}_{2}$ & $\mathrm{y}=-5 \mathrm{E}-07 \mathrm{x} 2+0.0014 \mathrm{x}+2.0328$ & $\mathrm{R}=0.9706$ \\
Biennial shoot & $\mathrm{VPD}(10-6)$ & $\mathrm{CO}_{2}$ & $\mathrm{y}=-8 \mathrm{E}-08 \mathrm{x} 2+0.0007 \mathrm{x}+2.0685$ & $\mathrm{R}=0.9617$ \\
Annual shoots & $\mathrm{E}(\mathrm{H} 2 \mathrm{O}) /(\mathrm{mol} \cdot \mathrm{m}-2 \cdot \mathrm{s}-1)$ & $\mathrm{CO}_{2}$ & $\mathrm{y}=0.1905 \mathrm{Ln}(\mathrm{x})+0.5453$ & $\mathrm{R}=0.9715$ \\
Biennial shoot & $\mathrm{E}(\mathrm{H} 2 \mathrm{O}) /(\mathrm{mol} \cdot \mathrm{m}-2 \cdot \mathrm{s}-1)$ & $\mathrm{CO}_{2}$ & $\mathrm{y}=0.196 \operatorname{Ln}(\mathrm{x})+0.4376$ & $\mathrm{R}=0.9758$ \\
Annual shoots & $\mathrm{PN}(\mathrm{CO} 2) /(\mu \mathrm{mol} \cdot \mathrm{m}-2 \cdot \mathrm{s}-1)$ & $\mathrm{CO}_{2}$ & $\mathrm{y}=1.2852 \mathrm{Ln}(\mathrm{x})-2.3522$ & $\mathrm{R}=0.9709$ \\
Biennial shoot & $\mathrm{PN}(\mathrm{CO} 2) /(\mu \mathrm{mol} \cdot \mathrm{m}-2 \cdot \mathrm{s}-1)$ & $\mathrm{CO}_{2}$ & $\mathrm{y}=1.363 \operatorname{Ln}(\mathrm{x})-3.3119$ & $\mathrm{R}=0.9758$ \\
Annual shoots & $\mathrm{WUE} /(10-3)$ & $\mathrm{CO}_{2}$ & $\mathrm{y}=0.433 \operatorname{Ln}(\mathrm{x})+0.5092$ & $\mathrm{R}=0.9543$ \\
Biennial shoot & $\mathrm{WUE} /(10-3)$ & $\mathrm{CO}_{2}$ & $\mathrm{y}=0.508 \operatorname{Ln}(\mathrm{x})-0.1157$ & $\mathrm{R}=0.9787$ \\
\hline
\end{tabular}

